TITLE:

\title{
Rituximab-combination chemotherapy achieves a 10th cycle of remission for Burkitt's lymphoma.
}

\section{$\operatorname{AUTHOR}(S)$ :}

Umeda, Katsutsugu; Fujino, Hisanori; Saida, Satoshi; Kato, Itaru; Hiramatsu, Hidefumi; Yamada, Tomomi; Hori, Toshinori; Adachi, Souichi; Heike, Toshio; Watanabe, Kenichiro

\section{CITATION:}

Umeda, Katsutsugu ... [et al]. Rituximab-combination chemotherapy achieves a 10th cycle of remission for Burkitt's lymphoma.. Pediatrics international 2015, 57(2): e30-e33

\section{ISSUE DATE:}

2015-04-13

\section{URL:}

http://hdl.handle.net/2433/200686

\section{RIGHT:}

This is the peer reviewed version of the following article: Umeda, K., Fujino, H., Saida, S., Kato, I., Hiramatsu, H., Yamada, T., Hori, T., Adachi, S., Heike, T. and Watanabe, K.-1. (2015), Rituximab-combination chemotherapy achieves a 10th cycle of remission for Burkitt's lymphoma. Pediatrics International, 57: e30-e33, which has been published in final form at http://dx.doi.org/10.1111/ped.12524. This article may be used for non-commercial purposes in accordance with Wiley Terms and Conditions for Self-Archiving.; The full-text file will be made open to the public on 13 APR 2016 in accordance with publisher's 'Terms and Conditions for Self-Archiving'.; この論文は出版社版でありません。引用の際には出版社版 をご確認ご利用ください。; This is not the published version. Please cite only the published version. 


\section{Patient Report}

\section{Rituximab-combination chemotherapy achieves a tenth cycle of remission for Burkitt's}

\section{lymphoma}

Running head: Rituximab-combination chemotherapy for Burkitt’s lymphoma

KATSUTSUGU UMEDA, MD ${ }^{1}$, HISANORI FUJINO, MD², SATOSHI SAIDA, MD ${ }^{1}$, ITARU

KATO, MD ${ }^{1}$, HIDEFUMI HIRAMATSU, MD ${ }^{1}$, TOMOMI YAMADA, MD ${ }^{3}$, TOSHINORI

HORI, MD ${ }^{3,4}$, SOUICHI ADACHI, MD ${ }^{5}$, TOSHIO HEIKE, $\mathrm{MD}^{1}$ and KEN-ICHIRO

WATANABE, $\mathrm{MD}^{1}$

${ }^{1}$ Department of Pediatrics, Graduate School of Medicine, Kyoto University, 54 Kawahara-cho,

Shogoin, Sakyo-ku, Kyoto 606-8507, Japan

${ }^{2}$ Department of Pediatrics, Osaka Red Cross Hospital, 5-30 Fudegasaki-cho, Tennoji-ku, Osaka

543-8555, Japan

${ }^{3}$ Advanced Medical Research Center, Aichi Medical University School of Medicine, 1-1

Yazakokarimata, Nagakute, Aichi 480-1195, Japan

${ }^{4}$ Department of Pediatrics, Aichi Medical University School of Medicine, 1-1 Yazakokarimata, 
Nagakute, Aichi 480-1195, Japan

${ }^{5}$ Department of Human Health Science, Graduate School of Medicine, Kyoto University, 53

Kawahara-cho, Shogoin, Sakyo-ku, Kyoto 606-8507, Japan

*Corresponding author: Katsutsugu Umeda

Department of Pediatrics, Graduate School of Medicine, Kyoto University, 54 Kawahara-cho,

Shogoin, Sakyo-ku, Kyoto, 606-8507, Japan

Phone: +81-75-751-3290; Fax: +81-75-752-2361; Email: umeume@kuhp.kyoto-u.ac.jp

Abstract word count: 147

Number of text pages: 6

Text word count: 813

Number of Tables and Figures: 1 Figure, 2 Tables

Number of reference pages: 2

Number of Figure legends: 1 


\section{Abstract}

A 14-year-old girl with multiple intra-abdominal tumors was diagnosed with stage III Burkitt's lymphoma. She achieved complete remission after multi-drug chemotherapy; however, she relapsed after six courses. Autologous peripheral blood stem cells (PBSC) or allogeneic PBSC harvested from an HLA-identical sibling were insufficient, and her family did not agree to bone marrow collection from the sibling. Although the patient exacerbated nine times (the relapses involved intra-abdominal organs or bone) during the following 4 years and 7 months, treatment with rituximab monotherapy or in combination with ifosphamide, carboplastin, and etoposide, or local irradiation (33.8 to 40.0 Gy) to treat the bone metastases, proved effective, resulting in complete or partial remission. The patient has been in a tenth cycle of remission lasting 1 year and 6 months and did not require transplantation. Thus, a chemotherapy regimen including rituximab might be effective for Burkitt’s lymphoma in patients experiencing multiple relapses.

Key words: Burkitt’s lymphoma, chemotherapy, relapse, rituximab 


\section{Introduction}

The advent of intensive multi-drug chemotherapy has led to very high survival rates for pediatric patients with Burkitt's lymphoma ${ }^{1,2}$. However, the prognosis for relapsed or refractory patients remains poor; the event-free survival of patients undergoing autologous or allogeneic transplantation is less than $30 \%$, and few patients that do not undergo transplantation survive long-term ${ }^{3}$. Recent reports show the efficacy of rituximab-combination chemotherapy as a first-line or salvage therapy for various types of CD20-positive non-Hodgkin's lymphoma, including Burkitt’s lymphoma ${ }^{4-7}$. Here, we report a pediatric case of Burkitt’s lymphoma for whom rituximab-combination chemotherapy was effective after each exacerbation. The patient is currently in a tenth cycle of remission lasting 1 year and 6 months and has not required transplantation. 


\section{Case Report}

A 14-year-old girl was admitted to our hospital complaining of worsening abdominal pain, abdominal distension, and dyspnea. Laboratory examination showed marked elevation of LDH (4078 IU/L), uric acid (20.0 mg/dL), and soluble IL-2R (2140 IU/mL). An EBV antibody test suggested previous infection and an HIV antibody test was negative. Abdominal computed tomography (CT) revealed large ovarian tumors and multiple intra-abdominal disseminations with massive ascites (Figure, panel A). Histological examination of the intra-abdominal tumors revealed monotonous infiltration by large lymphoid cells with a high N/C ratio; these cells were positive for CD10, CD20, Bcl-6, and MUM1 (Figure, panel D and data not shown). The MIB-1 labeling index was almost 100\% and EBER was negative. Examination of a bone marrow aspirate and a cerebrospinal fluid sample revealed no metastatic disease. Detection of the IgH/c-Myc rearrangement by fluorescence in situ hybridization (FISH) led to a diagnosis of group III Burkitt’s lymphoma. The patient was then treated with six courses of multi-drug chemotherapy according to the Japanese Pediatric Leukemia/Lymphoma Study Group B-NHL03 Study protocol ${ }^{2}$. All measurable intra-abdominal lesions disappeared after two treatment courses.

During the 4 years and 7 months after the initial chemotherapy protocol the patient experienced nine exacerbations (involving the intra-abdominal organs or bones), which were 
confirmed by adnominal MRI or ${ }^{18} \mathrm{~F}$-fluorodeoxyglucose positron emission tomography-CT scans (Figure, panels B and C and Table 1). Histological and/or FISH analysis of biopsy samples confirmed the first, second, and seventh exacerbations (Figure, panels E and F) ${ }^{8}$. After the first exacerbation (involving the ileocecum and left femur), the patient was treated with seven courses of ICE (ifosphamide, $2500 \mathrm{mg} /$ day for 3 days; carboplatin, $450 \mathrm{mg} /$ day for 1 day; and etoposide, $150 \mathrm{mg} /$ day for 3 days), ICE combined with rituximab (375 mg/m²; R-ICE) ${ }^{4}$, or rituximab monotherapy, all of which resulted in partial remission (PR). Insufficient autologous peripheral blood stem cells (PBSC) were harvested after the third round of ICE therapy. Unfortunately, insufficient allogeneic PBSC were harvested from an HLA-identical sibling and her family would not agree to bone marrow collection from the sibling. Therefore, each exacerbation was treated with rituximab (either alone or as part of the R-ICE regimen), combined with local irradiation (33.8-40.0 Gy) to treat the bone metastases. This treatment was effective and resulted in either complete remission (CR) or PR. During treatment with rituximab and/or combination chemotherapy, any severe adverse effects were not observed. To date, the patient is alive and in her tenth cycle of remission, which has lasted for 1 year and 6 months. No transplantation has been performed. 


\section{Discussion}

Due to a very high proliferation rate, patients with Burkitt’s lymphoma often develop chemotherapy-resistant clones. Therefore, the event-free survival of patients with relapsed Burkitt’s lymphoma ranges from $10-20 \%$, despite the availability of several conventional salvage chemotherapy regimens, no patients survive long-term without an autologous or allogeneic transplantation ${ }^{3}$. Previous studies that used rituximab alone or in combination with chemotherapy to treat relapsed or refractory Burkitt's lymphoma showed a CR + PR of 57$100 \%^{4-7}$; a few cases are alive and in remission without transplantation (Table 2$)^{6,7}$. Interestingly, when the current received R-ICE therapy after each relapse, she achieved either CR or PR, suggesting that this regimen might be effective even for Burkitt's lymphoma patients that have experienced multiple exacerbations. Of concern is the increasing risk of etoposide-related secondary malignancy, and it will be required to develop other rituximab-containing chemotherapy. Furthermore, the addition of 30 Gy local irradiation seems to be effective for controlling bone metastasis, as previously reported ${ }^{9}$.

Relapse of rapidly proliferating Burkitt’s lymphoma usually occurs within 1 year of the initial diagnosis, whereas a clonally distinct tumor would develop secondarily as a late recurrence $\mathrm{e}^{10}$. The current patient experienced several early exacerbations within a short period of time; however, the length of the remissions increased after the fifth exacerbation (Table 1). 
Analysis of immunoglobulin heavy chain rearrangements identified the same rearrangement in tumor samples taken at the time of the initial diagnosis, first exacerbation, and seventh exacerbation, suggesting the same lymphoma clone contributed to all exacerbations (data not shown). Genome wide analysis of a large series of cases with a similar clinical course would provide new insights into the pathogenesis of Burkitt’s lymhoma. 


\section{References}

1. Molyneux EM, Rochford R, Griffin B, et al. Burkitt’s lymphoma. Lancet. 2012; 379: 1234-1244.

2. Tsurusawa M, Mori T, Kikuchi A, et al. Improved treatment results of children with B-cell non-Hodgkin lymphoma: a report from the Japanese Pediatric Leukemia/Lymphoma Study Group B-NHL03 Study. Pediatr. Blood. Cancer. 2014; 61: 1215-1221.

3. Philip T, Hartman O, Pinkerton R, et al. Curability of relapsed childhood B-cell non-Hodgkin's lymphoma after intensive first line therapy: a report from the Société Française d'Oncologie Pédiatrique. Blood. 1993; 81: 2003-2006.

4. Griffin TC, Weitzman S, Weinstein H, et al. A study of rituximab and ifosfamide, carboplastin, and etoposide chemotherapy in children with recurrent/refractory B-cell (CD20+) non-Hodgkin lymphoma and mature B-cell acute lymphoblastic leukemia: a report from the Children’s Oncology Group. Pediatr Blood Cancer. 2009; 52: 177-181.

5. de Vries MJ, Verrman AJ, Zwaan CM. Rituximab in three children with relapsed/refractory B-cell acute lymphoblastic leukemia/Burkitt non-Hodgkin’s lymphoma. Br. J. Haematol. 2004; 125: 414-415.

6. Attias D, Weitzman S. The efficacy of rituximab in high-grade pediatric B-cell lymphoma/leukemia: a review of available evidence. Curr. Opin. Pediatr. 2008; 20: 17-22.

7. Akbayran S, Doğan M, Akgün C, et al. Use of rituximab in three children with relapsed/refractory Burkitt lymphoma. Targ. Oncol. 2010; 5: 291-294.

8. Hamabara T, Umeda K, Noudomi S, et al. Utility of endoscopic ultrasound-guided fine needle aspiration for diagnosis of Burkitt lymphoma. Rinsho. Ketsueki. 2013; 54: 653-657.

9. Lister J, Miklos JA, Swerdlow SH, et al. A clonally distinct recurrence of Burkitt's lymphoma at 15 years. Blood. 1996; 88: 1407-1410. 
10. Sutciffe SB, Gospodarowicz MK, Bush RS, et al. Role of radiation therapy in localized non-Hodgkin’s lymphoma. Radiother. Oncol. 1985; 4: 211-223. 


\section{Figure legends}

Figure (A-C) Radiographic findings. Abdominal computed tomography (CT) at the time of disease onset revealed huge ovarian tumors and multiple intra-abdominal disseminations with massive ascites (A). ${ }^{18}$ F-fluorodeoxyglucose positron emission tomography-CT performed at the time of the second and seventh exacerbations showed abnormal uptake in the right scapula (B) and pancreatic body (C), respectively. Tumors are indicated by arrows. (D) Hematoxylin and eosin staining of a biopsy sample taken at the time of disease onset. (E) Immunostaining of a biopsy sample taken after the second exacerbation for CD20. Scale bars $=50 \mu \mathrm{m}$ in D and E. (F) Fluorescence in situ hybridization analysis for IgH and c-MYC in a biopsy sample taken after the seventh exacerbation. Arrows show fusion signals. 

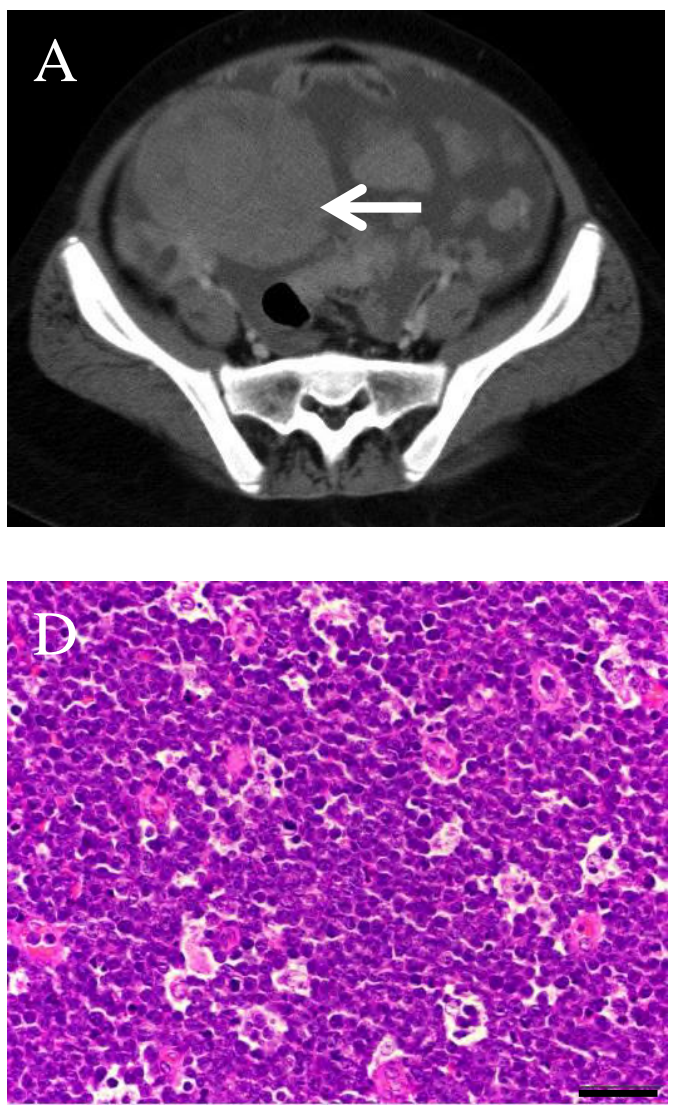

B
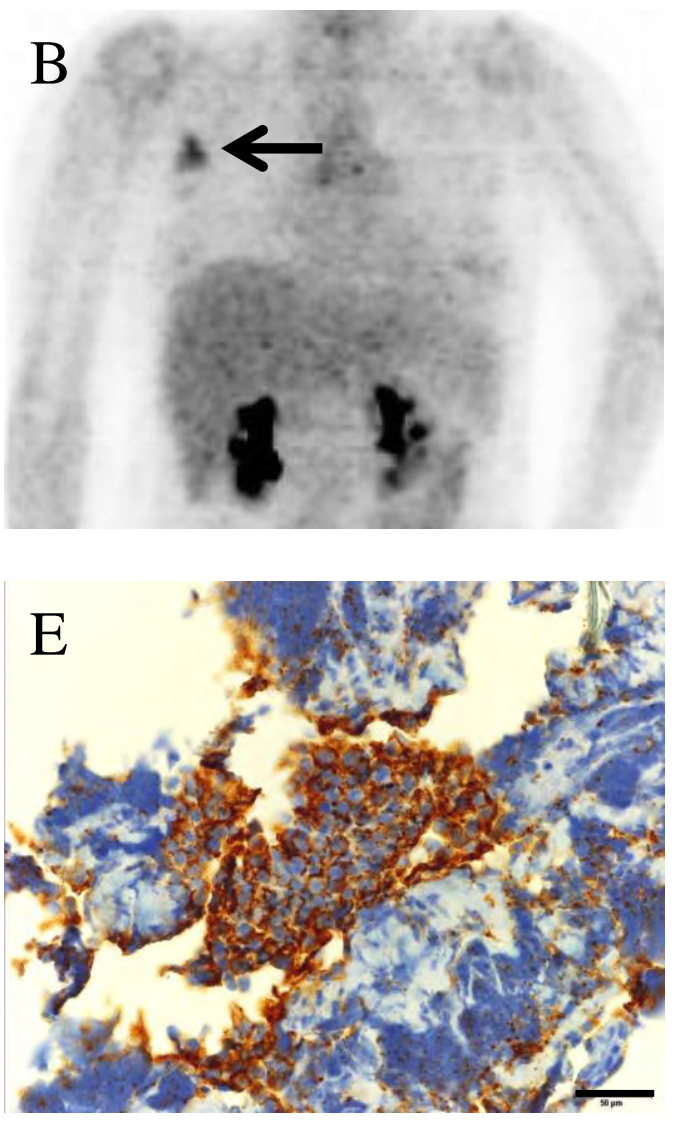
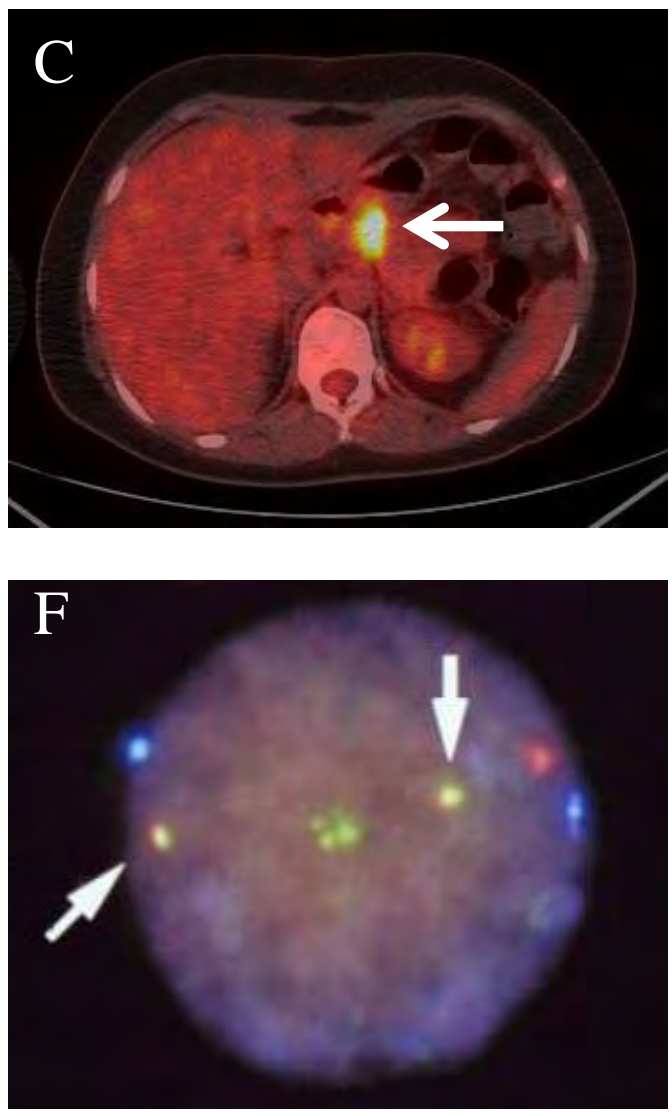
Table 1 Clinical course of the patient

\begin{tabular}{|c|c|c|c|c|c|c|}
\hline $\begin{array}{l}\text { Disease } \\
\text { status }\end{array}$ & $\begin{array}{l}\text { Time from } \\
\text { disease onset }\end{array}$ & $\begin{array}{l}\text { Duration from } \\
\text { the last treatment }\end{array}$ & Site of exacerbation & Chemotherapy & $\begin{array}{l}\text { Radiation } \\
\text { therapy }\end{array}$ & $\begin{array}{l}\text { Best } \\
\text { response }\end{array}$ \\
\hline 1st ECB & 6 months & 1 month & Ileocecum, left femur & R-ICE $\times 1$, ICE $\times 3, R \times 3$ & No & PR \\
\hline 2nd ECB & 1 year & 2 months & Right scapula & $\mathrm{R} \times 8$ & No & PR \\
\hline 3rd ECB & 1 year 4 months & 1 month & Right scapula & $\mathrm{R} \times 3$ & $40 \mathrm{~Gy} / 20 \mathrm{fr}$ & CR \\
\hline 4th ECB & 1 year 8 months & 1 month & Right ilium & $\mathrm{R} \times 1$ & $40 \mathrm{~Gy} / 20 \mathrm{fr}$ & PR \\
\hline 5th ECB & 1 year 10 months & 1 month & Bilateral femur & $\mathrm{R}-\mathrm{ICE} \times 3, \mathrm{R} \times 2$ & No & CR \\
\hline 6th ECB & 2 year 8 months & 4 months & Sacrum & No & 33.8Gy/13fr & CR \\
\hline 7th ECB & 3 year 7 months & 7 months & Pancreas body & $\mathrm{R}-\mathrm{ICE} \times 3, \mathrm{R} \times 2$ & No & CR \\
\hline 8th ECB & 4 year 3 months & 2 months & Left iliopsoas muscle & R-ICE×3 & No & CR \\
\hline 9th ECB & 5 year 1 month & 6 months & Left iliopsoas muscle & $\mathrm{R}-\mathrm{ICE} \times 3$ & No & $\mathrm{CR}$ \\
\hline
\end{tabular}

ECB, exacerbation; R, rituximab; ICE, ifosfamide+carboplatin+etoposide; PR, partial remission; CR, complete remission. 
Table 2 Clinical information for pediatric patients with refractory/relapsed Burkitt's lymphoma and B-ALL treated with rituximab

\begin{tabular}{|c|c|c|c|c|c|c|c|}
\hline $\begin{array}{l}\text { Patient } \\
\text { No. }\end{array}$ & $\begin{array}{l}\text { Gender/ } \\
\text { age }\end{array}$ & $\begin{array}{l}\text { Stage at } \\
\text { disease onset }\end{array}$ & Rituximab therapy & $\begin{array}{c}\text { Best } \\
\text { response }\end{array}$ & SCT & Outcome & Ref. \\
\hline 1 & $\mathrm{M} / 4$ & IV & $\mathrm{R}$ & CR & Allo & Died in CCR (cGVHD) & 5 \\
\hline 2 & $\mathrm{M} / 6$ & III & $\mathrm{R}$ & $\mathrm{PD}$ & No & DOD & 5 \\
\hline 3 & $\mathrm{M} / 3$ & IV & $\mathrm{R}$ & SD & Auto & CCR (48 months) & 5 \\
\hline 4 & $\mathrm{~F} / 4$ & III & $\mathrm{R}$ & CR & No & CCR (126 months) & 6 \\
\hline 5 & $\mathrm{M} / 5$ & III & $\mathrm{R}$ & CR & No & CCR (12 months) & 6 \\
\hline 6 & $\mathrm{M} / 16$ & III & $\mathrm{R}$ & CR & No & CCR (30 months) & 6 \\
\hline 7 & $\mathrm{~F} / 9$ & IV & $\mathrm{R}+\mathrm{TIT}$ & CR & Allo & DOD & 5 \\
\hline 8 & $\mathrm{~F} / 4$ & III & R + NHL BFM 90 & CR & No & CCR (24 months) & 5 \\
\hline 9 & $\mathrm{M} / 12$ & IV & R + NHL BFM 95 & CR & Auto & CCR (12 months) & 5 \\
\hline 10 & $\mathrm{~F} / 9$ & IV & $\mathrm{R}+\mathrm{ICE}$ & $\mathrm{PD}$ & No & DOD & 4 \\
\hline 11 & $\mathrm{M} / 5$ & IV & $\mathrm{R}+\mathrm{ICE}$ & SD & No & DOD & 4 \\
\hline 12 & $\mathrm{~F} / 16$ & III & $\mathrm{R}+\mathrm{ICE}$ & PR & No & DOD & 4 \\
\hline 13 & $\mathrm{M} / 5$ & IV & $\mathrm{R}+\mathrm{ICE}$ & $\mathrm{CR}$ & Auto & CCR (30 months) & 4 \\
\hline 14 & $\mathrm{M} / 14$ & IV & $\mathrm{R}+\mathrm{ICE}$ & PR & No & DOD & 4 \\
\hline 15 & $\mathrm{M} / 15$ & III & $\mathrm{R}+\mathrm{ICE}$ & PR & Auto & CCR (26 months) & 4 \\
\hline 16 & $\mathrm{M} / 11$ & III & $\mathrm{R}+\mathrm{ICE}$ & $\mathrm{PD}$ & No & DOD & 4 \\
\hline 17 & $\mathrm{M} / 10$ & III & $\mathrm{R}+\mathrm{ICE}$ & $\mathrm{PD}$ & No & DOD & 4 \\
\hline 18 & $\mathrm{M} / 20$ & III & $\mathrm{R}+\mathrm{ICE}$ & CR & No & AWD (14 months) & 4 \\
\hline 19 & $\mathrm{M} / 9$ & III & $\mathrm{R}+\mathrm{ICE}$ & $\mathrm{PD}$ & No & DOD & 4 \\
\hline 20 & $\mathrm{~F} / 13$ & IV & $\mathrm{R}+\mathrm{ICE}$ & CR & Auto & CCR (18 months) & 4 \\
\hline 21 & $\mathrm{M} / 16$ & IV & $\mathrm{R}+\mathrm{ICE}$ & CR & Allo & CCR (20 months) & 4 \\
\hline 22 & $\mathrm{M} / 5$ & IV & $\mathrm{R}+\mathrm{ICE}$ & PR & No & DOD & 4 \\
\hline 23 & $\mathrm{M} / 14$ & IV & $\mathrm{R}+\mathrm{ICE}$ & $\mathrm{PR}$ & No & DOD & 4 \\
\hline Our case & $\mathrm{F} / 14$ & III & $\mathrm{R}+\mathrm{ICE}$ & CR & No & CCR (18 months) & \\
\hline
\end{tabular}

$\mathrm{R}$, rituximab; TIT, triple intrathecal therapy; BFM, Berlin-Frankfurt-Munster; ICE, ifosfamide+carboplatin+etoposide; PD, progressive disease; SD, stable disease; PR, partial remission; CR, complete remission; Auto, autologous transplantation; Allo, allegeneic transplantation; cGVHD, chronic graft-versus-host disease; CCR, continuous complete remission; DOD, died of disease; AWD, alive with disease. 


\begin{tabular}{|c|c|c|c|}
\hline Patient No. & Gender/age & Stage at the onset & Rituximab therapy \\
\hline 1 & $\mathrm{M} / 4$ & IV & $\mathrm{R}$ \\
\hline 2 & $\mathrm{M} / 6$ & III & $\mathrm{R}$ \\
\hline 3 & $\mathrm{M} / 3$ & IV & $\mathrm{R}$ \\
\hline 4 & $\mathrm{~F} / 4$ & III & $\mathrm{R}$ \\
\hline 5 & $\mathrm{M} / 5$ & III & $\mathrm{R}$ \\
\hline 6 & $\mathrm{M} / 16$ & III & $\mathrm{R}$ \\
\hline 7 & $\mathrm{~F} / 9$ & IV & $\mathrm{R}+\mathrm{TIT}$ \\
\hline 8 & $\mathrm{~F} / 4$ & III & $\mathrm{R}+\mathrm{NHL}$ BFM 90 \\
\hline 9 & $\mathrm{M} / 12$ & IV & R + NHL BFM 95 \\
\hline 10 & $\mathrm{~F} / 9$ & IV & $\mathrm{R}+\mathrm{ICE}$ \\
\hline 11 & $\mathrm{M} / 5$ & IV & $\mathrm{R}+\mathrm{ICE}$ \\
\hline 12 & $\mathrm{~F} / 16$ & III & $\mathrm{R}+\mathrm{ICE}$ \\
\hline 13 & $\mathrm{M} / 5$ & IV & $\mathrm{R}+\mathrm{ICE}$ \\
\hline 14 & $\mathrm{M} / 14$ & IV & $\mathrm{R}+\mathrm{ICE}$ \\
\hline 15 & $\mathrm{M} / 15$ & III & $\mathrm{R}+\mathrm{ICE}$ \\
\hline 16 & M/11 & III & $\mathrm{R}+\mathrm{ICE}$ \\
\hline 17 & $\mathrm{M} / 10$ & III & $\mathrm{R}+\mathrm{ICE}$ \\
\hline 18 & $\mathrm{M} / 20$ & III & $\mathrm{R}+\mathrm{ICE}$ \\
\hline 19 & $\mathrm{M} / 9$ & III & $\mathrm{R}+\mathrm{ICE}$ \\
\hline 20 & $\mathrm{~F} / 13$ & IV & $\mathrm{R}+\mathrm{ICE}$ \\
\hline 21 & $\mathrm{M} / 16$ & IV & $\mathrm{R}+\mathrm{ICE}$ \\
\hline 22 & $\mathrm{M} / 5$ & IV & $\mathrm{R}+\mathrm{ICE}$ \\
\hline 23 & $\mathrm{M} / 14$ & IV & $\mathrm{R}+\mathrm{ICE}$ \\
\hline Our case & $\mathrm{F} / 14$ & III & $\mathrm{R}+\mathrm{ICE}$ \\
\hline
\end{tabular}

\begin{tabular}{|c|c|c|c|}
\hline & SCT & Outcome & Ref. \\
\hline$\overline{\mathrm{CR}}$ & Allo & Died in CCR (cGVHD) & 1 \\
\hline PD & No & DOD & 1 \\
\hline SD & Auto & CCR (48 months) & 1 \\
\hline CR & No & CCR (126 months) & 2 \\
\hline CR & No & CCR (12 months) & 2 \\
\hline CR & No & CCR (30 months) & 2 \\
\hline CR & Allo & DOD & 1 \\
\hline CR & No & CCR (24 months) & 1 \\
\hline CR & Auto & CCR (12 months) & 1 \\
\hline PD & No & DOD & 3 \\
\hline SD & No & DOD & 3 \\
\hline PR & No & DOD & 3 \\
\hline CR & Auto & CCR (30 months) & 3 \\
\hline PR & No & DOD & 3 \\
\hline PR & Auto & CCR (26 months) & 3 \\
\hline PD & No & DOD & 3 \\
\hline PD & No & DOD & 3 \\
\hline CR & No & AWD (14 months) & 3 \\
\hline PD & No & DOD & 3 \\
\hline CR & Auto & CCR (18 months) & 3 \\
\hline $\mathrm{CR}$ & Allo & CCR (20 months) & 3 \\
\hline PR & No & DOD & 3 \\
\hline PR & No & DOD & 3 \\
\hline CR & No & CCR (?? months) & \\
\hline
\end{tabular}

